\title{
Ciudad obrera: persistencias y variaciones en las significaciones del espacio. El caso de la siderúrgica Huachipato y su influencia en el desarrollo urbano del Gran Concepción ${ }^{1}$
}

Alejandra Brito. Universidad de Concepción, Concepción, Chile. Rodrigo Ganter. Universidad de Concepción, Concepción, Chile.

RESUMEN | El objetivo de este trabajo es discutir la conformación de una subjetividad espacial vinculada con una manera de habitar el territorio; una subjetividad espacial centrada en la experiencia vivida del territorio, la percepción actual de él y la proyección del mismo. El objeto en que se despliega este enfoque está constituido por los espacios residenciales que formaron parte de la iniciativa de construcción de vivienda piloteada por la Siderúrgica de Huachipato a partir de los años cuarenta del siglo pasado. Nos situamos en las transformaciones en la "episteme" de las ciencias sociales y las humanidades, que han ido operando en la actualidad en lo que se conoce como el "giro geográfico", perspectiva capaz de generar una interesante discusión y propuesta que toma distancia del positivismo y el racionalismo geográfico. Este punto de vista está posibilitando un importante retorno a las preguntas por la experiencia geográfica sensible y más cercana a las identidades que componen, practican, significan y producen sociocultural e históricamente los territorios, los espacios y sus memorias.

PALABRAS CLAVE | industrialización, desarrollo territorial, historia urbana.

ABSTRACT | This paper discusses the formation of spatial subjectivity associated with a particular way of inhabiting territories, focusing on the way in which these territories are experienced and perceived, both currently and as a projection of the future. This approach is applied to the residential spaces of the housing project developed by the Huachipato Iron and Steel industry in Concepcion, Chile, starting in the 1940's. In this way, the viewpoint adopted is that of the on-going "epistemic transformations" of the social sciences and humanities, known as the "geographic turn". This shift opens an interesting discussion and has generated proposals that are detached from geographic rationalism and positivism, thus allowing for a significant return to issues regarding geographic sensitive experience - an experience closer to the identities that produce, practice, give form and significance to territories, spaces and memories, both socio-culturally and historically.

KEY WORDS | industrialization, territorial development, urban history.

Recibido el 13 de marzo de 2013, aprobado el 9 de octubre de 2013

E-mail: Alejandra Brito, abrito@udec.cl | Rodrigo Ganter, rganter@udec.cl

$1 \quad$ Este artículo se inscribe en el Proyecto Fondecyt $N^{\circ} 1111007$. 


\section{Introducción}

El texto que aquí presentamos se sitúa en el cruce narrativo y de lenguajes inscrito en el campo de lo interdisciplinario, en un intento de hacer dialogar los saberes procedentes de la historiografía, la sociología, la psicología, la antropología, la arquitectura, el urbanismo y el llamado "giro geográfico". Así, nos aproximamos -tanto en la forma como en el fondo- a la construcción de una mirada compleja y procesual del objeto de estudio que aquí ponemos en juego. Se trata de una exploración que indaga en la conformación histórica y singular de un emplazamiento urbano de carácter obrero en el "Gran Concepción"2, recurriendo para ello a la discusión sobre los modelos y estrategias de desarrollo que impulsaron la materialización de dicho proyecto desde mediados de los años cuarenta hasta los setenta. Además, se abordan los beneficios y logros obtenidos por un grupo de familias que llegaron a constituirse en una elite obrera y que, con la colaboración de la Siderúrgica Huachipato, obtuvieron su vivienda propia al interior de un emplazamiento que estaba notablemente equipado y conectado con diversos e importantes centros urbanos de la región. Fueron familias que desarrollaron un potente sentido de pertenencia "en" y "con" el espacio, un espacio cuya valoración y el orgullo que despertó en sus habitantes no se deja diluir con facilidad, pese al tiempo transcurrido y a las grandes transformaciones experimentadas por nuestra sociedad en los años recientes.

\section{Apuntes sobre el giro geográfico y su perspectiva interpretativa}

En los últimos años, la noción de espacio ha venido a revitalizar la discusión al interior de los estudios urbanos contemporáneos, pues comienza a descentrarse la idea de espacio como contenedor pasivo de los procesos humanos, desplazada por una concepción de espacio como campo dinámico y creador-productor de experiencias sociales. El geógrafo E. Soja (1997) -siguiendo a H. Lefebvre- argumenta que en el último tiempo se viene dando en la investigación social un reequilibrio de los tres aspectos básicos que componen la experiencia humana: la espacialidad, la historicidad y la socialidad (p. 72). El planteamiento de Soja se sustenta en lo que él denomina trialéctica de la espacialidad (p. 74); y es precisamente en torno a este punto que distingue tres tipos de espacio: i) el espacio percibido: es aquel espacio constituido por el mundo físico o material; ii) el espacio concebido: es aquel espacio constituido por el mundo de las representaciones sociales, el espacio de las construcciones imaginarias; iii) el espacio vivido: es aquel espacio constituido por la experiencia cotidiana y, en ese sentido, es un espacio de la diferencia cultural. Por lo mismo, se encuentra considerablemente modelado por la trama de poderes imbricados al interior de la experiencia vivida y que intentan controlar la subjetividad.

2 Usamos el concepto de "Gran Concepción" siguiendo los planteamientos del geógrafo Hilario Hernández, quien considera que las localidades urbanas de Concepción, Talcahuano, Penco, Lirquén, Tomé, Chiguayante, San Pedro, Lota y Coronel deben ser comprendidas en conjunto, ya que su devenir histórico está unido al proceso de modernización de mediados del siglo xix en la zona (Vivallos \& Brito, 2011). 
Por ello, también es posible asumirlo como un espacio de fricción y conflicto permanente entre los diagramas del poder que modelan la subjetividad y las prácticas de subversión del mismo. De ahí que, en el último tiempo, la relación entre identidad y territorio haya venido adquiriendo una mayor complejidad, derivada de las actuales mutaciones del espacio-tiempo y de las nuevas modalidades de movilidad y comunicación desplegadas por los actores en un escenario social de alto dinamismo.

Si bien no es posible desconocer los procesos asociados con las dinámicas de desterritorialización derivadas de las fuerzas de la globalización, tampoco lo es soslayar la importancia que posee el territorio, en tanto construcción sociocultural y práctica colectiva mediante la cual los sujetos arman sus pertenencias, arraigos y memorias compartidas, aunque sea de modo precario y provisorio, a causa del actual contexto de cambios e incertidumbres al cual se encuentra expuesta la vida cotidiana. Tal imposibilidad se hace particularmente evidente si se piensa en los actuales procesos de segmentación territorial de las ciudades, donde el territorio puede ser pensado como recurso de integración e identificación al interior del propio grupo de pertenencia. En esta línea, la antropóloga Rossana Reguillo (1991) distingue el espacio físico del espacio construido. Siendo el espacio un componente genético de la estructura identitaria de los actores urbanos, es posible distinguir dos dimensiones en él: la dimensión dada del espacio, esto es, la ciudad como espacio físico preexistente a la subjetividad social; y la dimensión construida del espacio, esto es, el territorio como espacio que constituye una extensión de la propia subjetividad y que, simultánea y cotidianamente, es practicado por las personas, donde destaca el elemento de la grupalidad y la devolución de una imagen referida a quienes lo habitan.

El territorio, entonces, no puede de ninguna manera considerarse como contenedor de hechos sociales, como mero escenario o telón de fondo en el que se desarrolla la acción. El territorio se nos aparece como una construcción social en la que se entretejen lo material y lo simbólico, que se interpretan para dar forma y sentido a la vida del grupo, que se esfuerza por transformar mediante actos de apropiación -inscribir en el territorio las huellas de la historia colectiva- el espacio anónimo en un espacio próximo pleno de sentido para él mismo (Reguillo, 1996, p. 78).

En una perspectiva ensamblada con la anterior, Harold Proshansky elabora la noción de place-identity, es decir, la identidad de lugar (Proshansky, 1978; y Proshansky, Fabian \& Kaminoff, 1983). Esta última operaría como una subestructura de la identidad de self, y consiste en la trama de significaciones referidas a los lugares o espacios donde el actor desarrolla su vida cotidiana. Se manifiesta como la capacidad de tejer vínculos emocionales y pertenencias significativas asociadas con determinados territorios o lugares específicos y memorables, como, por ejemplo, la comuna; o, en nuestro caso, el barrio, la villa, la población; y más específicamente, con determinados emplazamientos o zonas dentro de ese mismo escenario, como una cancha de fútbol, una sede vecinal, una plaza o una esquina concreta.

Los vínculos territoriales son tan importantes y significativos como las relaciones sociales que un individuo puede establecer en el transcurso de su vida. En la base de esta estructura se encuentra el "pasado ambiental" de la persona, esto 
es, el cúmulo de recuerdos espacializados que le permiten construir significados y sentidos compartidos con otros. Este almacén socioemocional -del que el actor es poco consciente, a menos que perciba su identidad amenazada- le permite identificar y adjudicarles determinados atributos significativos a los entornos nuevos y que se vinculan de alguna manera con su "pasado ambiental", vale decir, con su memoria espacializada, favoreciendo un sentido de familiaridad y una sensación de estabilidad y seguridad en y con el ambiente. Asimismo, contribuye a orientar y a entregar signos respecto de cómo actuar y comportarse en un espacio o escenario específico asociado a un campo complejo de interacciones sociales; junto con ello, ayuda a definir el grado de apropiación o la capacidad para modificar el entorno por parte de los actores sociales (Valera, 1994).

En este plano, el campo de estudio ligado a la Geografía de la Vida Cotidiana (GVC) retoma los aportes en torno a la metáfora dramatúrgica del sociólogo interaccionista Erving Goffman (1971), que facilitaron el abordaje de prácticas cotidianas fijadas en el espacio y en un lugar, por más efímeras y fugaces que fuesen. En esa línea, el estudio de las prácticas cotidianas centrado en el análisis de los escenarios indaga en los espacios y en los tiempos en los cuales los sujetos desarrollan encuentros, intercambios, fricciones y redes territoriales con otras personas. Así, la GVC puede ser abordada como aquel conocimiento de sentido común de los actores que orienta sus decisiones, desde cosas muy simples, como lugares para transitar, para descansar, para reunirse, para celebrar, a los lugares y rutas que se evitan, los mismos que son valorados o despreciados. Este enfoque incorpora el saber que influye a la hora de escoger una determinada ruta para ir al trabajo o a divertirse, como también sobre ese conocimiento que orienta decisiones más importantes, como dónde vivir o si cambiarse o no de barrio (Lindon, 2006).

Por su parte, Seamon (1979) incluye en sus estudios los encuentros, en el marco de lo que él denomina la "geografía del mundo de la vida". Este autor utiliza el concepto de "encuentro" creado por Goffman (1971), quien lo trabaja a partir de las interacciones cara a cara, asumiéndolas como encuentros entre personas, que ocurren en situaciones de interacción ubicadas en escenarios concretos, en territorios específicos. Es así que, para el campo de estudio configurado por este enfoque geográfico emergente, la dimensión espacio-tiempo (territorio-historia/barriobiografía) adquiere una significación estratégica. Esta perspectiva goffmaniana ha sido trabajada también por autores como Gumuchian (1991), quien enfoca el territorio como un escenario donde se despliegan representaciones en sucesivos actos. Otros geógrafos, como Tello (2003), también han retomado esta mirada para plantear la figura del "actor territorializado" o el "actor geográfico".

En América Latina destacan los aportes de la geógrafa mexicana Alicia Lindón (2006) y sus contribuciones sobre subjetividad espacial. En este enfoque se concibe el espacio no como un container neutro e inerte -es decir, ni como localización ni únicamente como un producto material y físico-, sino como vivencia o experiencia. Esta concepción experiencial y narrativa del espacio implica una coexistencia y una sinergia entre el plano material (físico), el plano biográfico (identidades territoriales), y el plano sociohistórico (estructural). Se da, así, un replanteo de la narrativa geográfica tradicional, un nuevo enfoque iniciado a partir de los ańos setenta, que se 
vincula con diversas transformaciones en la "episteme" de las ciencias sociales y de las humanidades. Tales transformaciones han ido operando lo que en la actualidad se conoce como el "giro geográfico", el que instala una interesante propuesta que toma distancia del positivismo y el racionalismo geográfico (Hiernaux \& Lindon, 2006). Tal viraje está posibilitando un cuantioso retorno a las preguntas por la experiencia geográfica sensible y más cercana a las identidades que componen, practican, significan y producen sociocultural e históricamente los territorios, los espacios y sus memorias.

Por último, existe también un giro consecutivo en lo que se presenta a la indagación geográfica, según ella los investigadores se ven confrontados a dos situaciones complementarias. La primera de ellas se refiere a la escala de los procesos estudiados, donde lo pequeño se torna la dimensión del espacio inteligible. La segunda situación se define por la relación del individuo con el espacio, que en esta perspectiva queda profundamente marcada por su "experiencia espacial", la que se encuentra teñida por lo sensible. Los y las geógrafas que se han introducido en esta vía han tenido, entonces, que acudir a aquellas disciplinas en las cuales la dimensión sensible ha mantenido una relevancia. De ahí que pensar en lo sensible es interrogar sobre el proceso mismo de la experiencia geográfica: esta no puede eludirse, ya que está en la base de nuestras decisiones y acciones sobre el espacio mismo y de nuestra relación con los demás, produciendo el tejido social. Así, las y los geógrafos se ven impulsados a comprender no solo cómo se percibe, se siente y se configura la experiencia, sino cómo se percibe y se construye en particular la experiencia del espacio que, por su naturaleza misma, resulta diferente de otros tipos de objetos percibidos (véase al respecto Hiernaux-Nicolas, 2008).

Desde esta manera nos interesa comprender las significaciones del espacio construido en vínculo con la Siderúrgica Huachipato, no solo para comprender su emplazamiento como espacio físico, sino fundamentalmente por la importancia que los sujetos le atribuyen al habitar en un lugar y un tiempo específico.

\section{Industrialización, movilidad social y despliegue urbano en el Gran Concepción}

A finales de los años treinta en Chile se hizo manifiesto un déficit importante en materia de equipamiento urbano e infraestructura, pues las ciudades de esa época no estaban preparadas para asimilar las explosivas dinámicas migratorias que llevaban ingentes cantidades de población rural hacia los centros urbanos. Sumado a ello -más bien, concomitante con ello-, fueron apareciendo fenómenos sociales y urbanos nuevos, como por ejemplo las "poblaciones callampa", altamente precarias y asentadas en las orillas de ríos y canales, en la periferia de las ciudades, sin servicios básicos y en condiciones de hacinamiento extremo.

Como consecuencia de los graves efectos de la crisis económica de los años treinta -Chile fue una de las naciones más afectadas por la Gran Depresión de 1929-, los gobiernos de la época adoptaron varias medidas de tipo económico, orientadas a desligar la economía nacional de los efectos y las presiones del mercado internacional. De ahí que el Estado tomase un gran protagonismo en la planificación 
estratégica de la economía nacional, convirtiéndose en un actor importante como generador de actividad productiva, económica, de desarrollo urbano e infraestructura. La llegada del Frente Popular al gobierno en 1938 fue decisiva para la instalación y legitimación de dicha lógica, pues mediante el Estado comenzó a generarse una nueva concepción del desarrollo y un impulso industrializador. Los objetivos de este proceso que se iniciaba apuntaban principalmente a la sustitución de importaciones y a la generación de un proceso de desarrollo social endógeno e interdependiente con esta nueva estructura económica. En este marco se inscribe la creación de la Corporación de Fomento de la Producción (CORfo), donde el Estado asumiría un rol empresarial en áreas estratégicas del desarrollo, materializado en la realización de obras públicas de gran envergadura. Entre los planes y estrategias más importantes, cabe destacar el plan de electrificación del país, uno de cuyos hitos fue la fundación de la Empresa Nacional de Electricidad (ENDESA), en 1944.

En ese mismo impulso desarrollista e industrializador se inscribe la creación de la Compañía de Acero del Pacífico (CAP), como empresa mixta. Entre las filiales de la cap estaba la Siderúrgica Huachipato, cuya construcción comenzó en 1946. Para Aliste (2011), el Gran Concepción fue el emplazamiento ideal en los años cincuenta para materializar y estimular la industria manufacturera nacional, cuyo impacto derivó en un incremento de población que fue localizándose en un territorio reducido y morfológicamente complejo. Este emplazamiento recogió también la experiencia industrializadora temprana de la zona, que en el siglo xix había sido un polo de desarrollo significativo en la industria agrícola (molinerías de trigo y vitivinicultura), la industria carbonífera, la industria textil y la de bienes de consumo (Pacheco, 2003; Mazzei de Grazia, 1997). La Siderúrgica Huachipato, emplazada entre Concepción y Talcahuano, no solo significó un cambio social y laboral, sino que también implicó una transformación en la propia configuración del territorio y de la ciudad, mediante la expansión y creación de nuevos espacios públicos, emplazamientos industriales, zonas residenciales, etcétera.

La expansión de la planta física de la ciudad a partir de los años cincuenta se explica fundamentalmente por el crecimiento industrial, que derivó en marcados patrones de "acreción" de nuevas áreas sobre los bordes de la ciudad (Pérez \& Salinas, 2007). Asimismo, el accionar de la Siderúrgica Huachipato y su impulso en la creación de nuevos espacios residenciales provocó que muchos de los profesionales que trabajaban en la empresa se orientaran a vivir en otras zonas urbanas distantes de los asentamientos próximos a la industria, como fue la zona de Pedro de Valdivia y el Barrio Universitario. Además, para un número importante de trabajadores técnicos y profesionales, que venían del extranjero (mayoritariamente de EE.UU.), la industria adquirió tres bloques de departamentos en la zona circundante a la plaza Perú, que en esos ańos estaba en plena construcción. Todo ello fue contribuyendo a expandir la ciudad, el comercio, los servicios, la vida urbana y la configuración paulatina de una conurbación de proyección y escala metropolitana.

En simultáneo con el proceso antes descrito, destaca el proyecto de la nueva ciudad obrero-industrial, particularmente reflejado en el caso de la Villa Presidente Ríos, reconocida como población Higueras. Se trata este de un proyecto emblemático, por constituir el primer ensayo del urbanismo modernista en Chile, que 
tendió a prever en el diseño urbano la articulación coherente de espacios como el vecindario, la comunidad y la ciudad, entendida esta última como unidad mayor y englobante de las dos anteriores (Fuentes, 2006; Fuentes \& Pérez, 2007).

El proceso de industrialización en la región del Biobío, desplegado de la mano de un actor como la empresa Huachipato, destacó por promover en sus trabajadores y familias las facilidades para adquirir una vivienda, educación, estabilidad laboral y, por sobre todo, movilidad social ascendente. De esta manera, se aseguraba una vivienda para el trabajador y su familia emplazada lo más cercana posible a su lugar de trabajo, evitando trayectorias de desplazamiento muy agobiantes y, en consecuencia, mejorando la calidad de vida de los residentes. Tras tal objetivo estaban también la idea predominante en la empresa, cual era mantener un ritmo de productividad sostenido y en ascenso, sin que se viera interrumpido por factores externos; $y$, en simultáneo, el impulso a la conformación de un sentimiento de pertenencia colectivo y de arraigo corporativo por parte de la fuerza de trabajo incorporada a la Siderúrgica Huachipato.

\section{FIgUra 1 | Plano del Concepción Metropolitano}

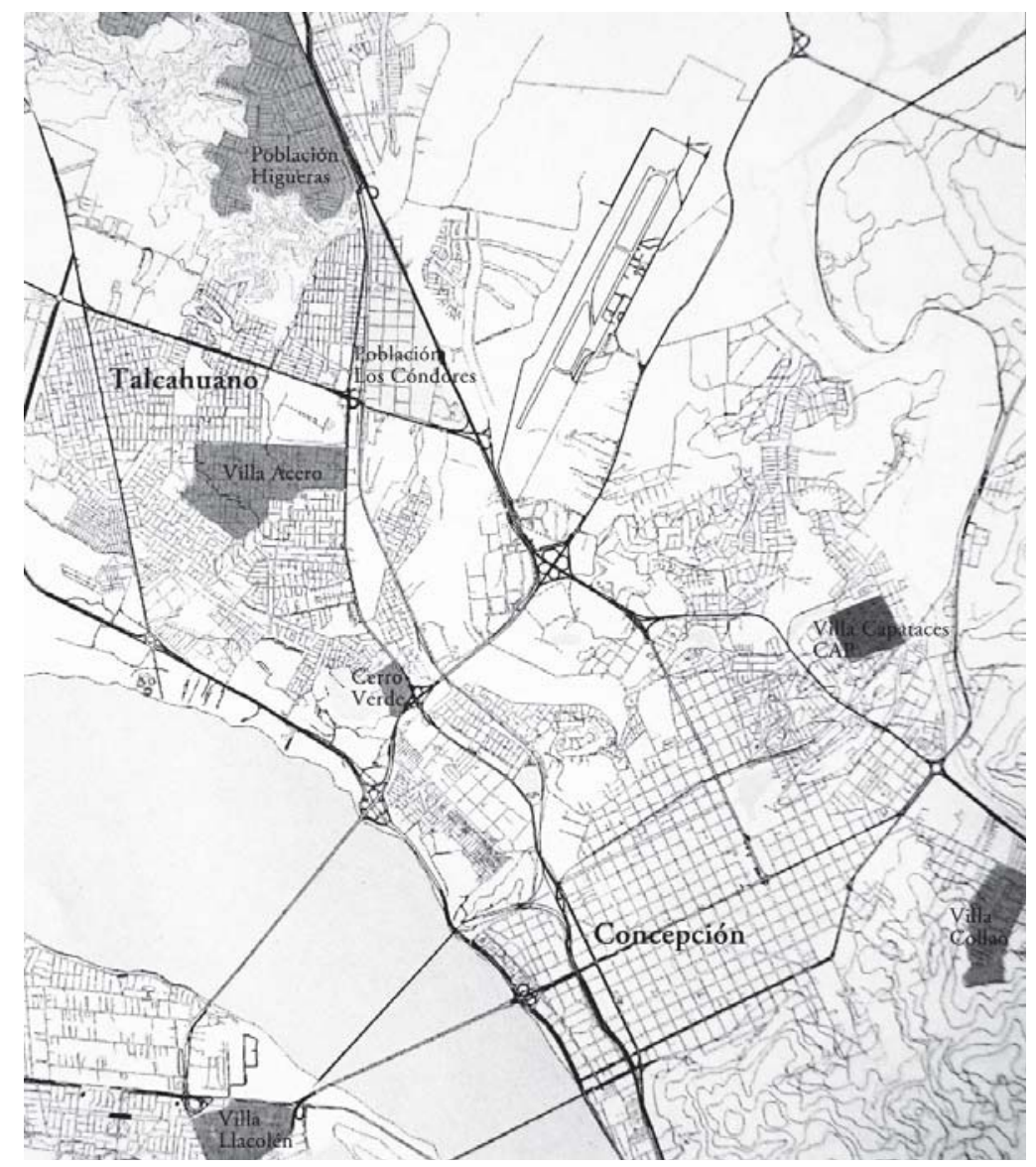

FUENTE ELABORACIÓN PROPIA 
El terreno de 983 hectáreas donde se levantó la nueva ciudad obrera estaba ubicado al borde del océano Pacífico y tenía las ventajas de ser una superficie plana, de poco valor comercial y escasas posibilidades de desarrollo agrícola, pero ello simultáneamente con altas posibilidades de combinar las zonas de edificación industrial con las habitacionales. Al mismo tiempo, el emplazamiento poseía la fortaleza de estar en una localización próxima a los centros de abastecimiento de materias primas necesarias para el funcionamiento de la industria, rutas que facilitaban el transporte de productos de exportación nacional e internacional e infraestructura portuaria próxima. Además, su localización proyectaba una excelente conectividad con los centros urbanos de Concepción, Talcahuano, Penco, etcétera, al estar adyacente a caminos y vías férreas que articulaban la nueva ciudad con dichos centros urbanos (Fuentes \& Pérez, 2007).

Concebida como una ciudad autosuficiente y a cuatro kilómetros de la planta industrial Huachipato, separada de ella por una cadena de cerros que le asignaban ventajas climáticas y la aislaban de la polución acústica y de gases, estaba "dividida en cuatro grandes poblaciones que contienen en su centro pequeńos mercados periféricos, escuela, parques cruzados y separados por amplias vías, llamadas avenidas, que se denominan Desiderio García, Alto Horno, Laminadores, Iquique, Quillay, Calle Seis y Calle Cinco" (Silva, 1967, p. 58). Desde un comienzo se proyectó para albergar a 20.000 habitantes (Fuentes, 2006), posibilitando la proximidad y el intercambio entre diferentes clases y segmentos sociales, lo que contribuyó a prefigurar un modelo de barrio y de desarrollo urbano que, a diferencia de ciudades como Santiago, no privilegió en los modos de vida urbana la segregación residencial y socioespacial, sino la mezcla y el intercambio. La construcción de este espacio urbano fue uno de los pilares al momento de definir las políticas de bienestar de la siderúrgica hacia sus trabajadores. Como lo expone Pablo Fuentes (2006), la Villa Presidente Ríos surgió como un ejercicio en la Universidad Católica, donde se diseñaría un proyecto "para 20.000 habitantes, 5.600 obreros y 1.090 empleados ocupados en la usina e industrias anexas, sus respectivas familias y la población necesaria para su abastecimiento y administración” (p. 31). La empresa se involucró en la idea de construir un moderno complejo habitacional, el que podía alcanzar 30.000 habitantes. En 1951 comenzó la construcción de la llamada Villa Presidente Ríos, y en 1953 se entregaron las primeras casas. Entre los objetivos de la empresa estaba el que los trabajadores se transformaran en propietarios de sus viviendas, para ello utilizó los distintos mecanismos públicos que permitían acceder a sistemas de financiamiento.

La documentación de la empresa nos muestra que desde que se comenzó a construir la planta se hizo evidente la preocupación por la construcción de viviendas y el desarrollo urbanístico. En 1947 la cap creó en Santiago la Oficina de Arquitectura, cuyo objetivo era encargarse de los proyectos del Campamento Obrero y de los edificios provisorios de la construcción. En 1948 se contrataron los servicios profesionales de los señores Larraín y Duhart, como arquitectos urbanistas (los mismos que confeccionaron el plano oficial del Gran Concepción) para realizar el plano urbano de la villa. La empresa se involucró directamente en la construcción, para esto puso al servicio de dicha actividad a un equipo de ingenieros; entre ellos "el 
Ingeniero, Sr. Ruperto Casanueva para proyectar los sistemas de alcantarillado, de agua potable y de drenaje; el Sr. Benjamín Vial para la formación del Plan Asistencial y Hospitalario; el Sr. Martín Bunster para la formación del plan escolar, el arquitecto, Sr. Federico Oehrens en el aspecto urbanístico, el Sr. Oscar Prager en el aspecto de arquitectura paisajista, etc." (Revista Huachipato, 2[15], diciembre 1954, p. 6; en adelante, solo Huachipato). Al cerrar la Oficina de Arquitectura en Santiago se creó en la misma población Higueras, en febrero de 1951, el Departamento de Habitaciones, cuyo objetivo era preocuparse directamente de las obras en ejecución en dicho lugar. En 1954 ya existía el Departamento de Industrias Anexas, Viviendas y Administración de Propiedades, el que se dividía en secciones, entre ellas estaba la de Arquitectura, Urbanismo y Plantaciones, encargada de los proyectos de construcción de casas y otros edificios de la empresa, que además gestionaba los diversos mecanismos de financiamientos fiscales y se encargaba de asesorar los proyectos de urbanización. Supervisaba la ejecución correcta de los proyectos habitacionales y de urbanización la sección de Construcciones y Urbanización (Huachipato, 2[15], diciembre 1954).

La formación de este importante núcleo urbano mostraba el empuje del proyecto y la forma en que la empresa y sus trabajadores se vinculaban para hacer posible uno de los emblemas del proyecto desarrollista, que consistía en formar un núcleo de trabajadores modernos, donde el sueño de la casa propia se transformaba en un símbolo. En julio de 1957 la revista Huachipato titulaba su editorial "Atacando el problema habitacional”, donde decía:

Las dos veces centenaria ciudad de Talcahuano se está rejuveneciendo: lo que hace sólo 10 años eran pastizales del fundo La Higuera está transformado en la Villa Presidente Ríos, en el más moderno sector de Talcahuano. Más de mil casas ya han sido levantadas en estos pocos años, gracias al esfuerzo y empuje de obreros y empleados de CAP y de la zona, que han luchado en estrecha cooperación con la administración de las industrias, la Corporación de la Vivienda, la Fundación de Viviendas de Emergencia y la Caja de Previsión de Empleados Particulares, para resolver el grave problema habitacional de la provincia. Cerca de 6.000 habitantes ya pueden vivir en la flamante Villa, la que seguirá creciendo para alcanzar una meta de 30.000 habitantes (Huachipato, 4[46], julio 1957, p. 3).

De manera recurrente se iba informando de la entrega paulatina de las casas a los trabajadores, los actos y ceremonias realizados; además, preocupaba a la empresa la toma de conciencia de los trabajadores en torno al cuidado del barrio, el mantener el entorno siempre limpio, cuidar las casas, las veredas, los juegos infantiles, las áreas verdes, etcétera.

La construcción de viviendas para los trabajadores de la CAP se extendió en los años sesenta hacia otros sectores de la ciudad, mostrando el aumento del espacio urbano que la empresa iba alcanzando. Así, el 29 de mayo de 1966 se entregaron oficialmente 146 casas construidas en el sector llamado Barrio Norte de Concepción, construidas por la Sociedad de Urbanización y Construcción de Capataces de la CAP. En la ceremonia fueron bendecidas las casas por un sacerdote y hablaron los representantes tanto de la empresa como de los trabajadores. Estas 146 casas eran solo las 
primeras de 439 planificadas para esa zona. De esa manera se iba dando cabida a un creciente número de trabajadores que, con el apoyo financiero de la empresa y de otros organismos, llegaban a ser propietarios de viviendas, consolidando un espacio urbano y posesionándose del territorio del que formaban parte.

FIgURA 2 Ceremonia de inauguración, Villa Higueras

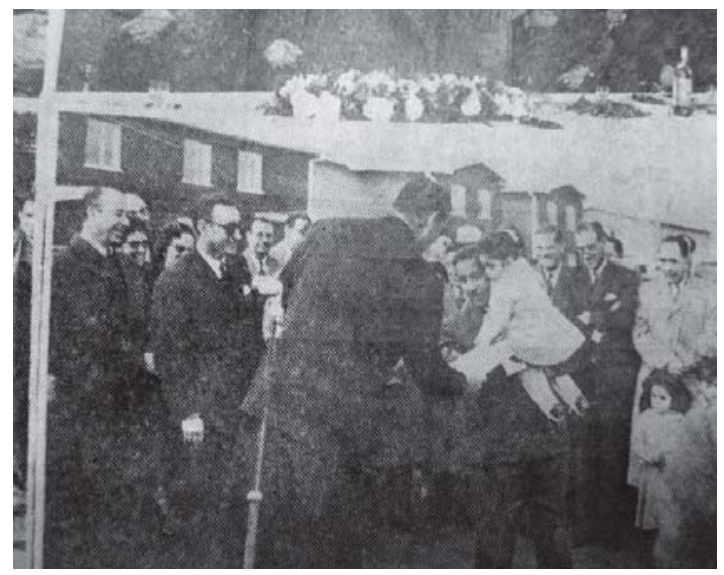

FUENTE HUACHIPATO, 4(47), AGOSTO I957, P. I 7

El acceder a alguna de las casas en construcción implicaba para el trabajador y su familia un esfuerzo importante, ya que las compraban por medio de distintos organismos y con el apoyo crediticio de la propia empresa. También existieron viviendas adquiridas por la empresa y destinadas a los habitantes del campamento que se levantó al iniciarse las obras de construcción de la planta. En 1957 se informaba que la empresa tenía 419 casas de dos, tres y cuatro dormitorios y que todas estaban asignadas. Estas casas se entregaban a trabajadores seleccionados en un proceso a cargo del Servicio Social de la empresa, y ellos las pagaban gradualmente mediante un descuento mensual por planilla, equivalente a un canon de arrendamiento que alcanzaba al 20\% de su salario. Los recursos mensuales se acumulaban hasta llegar a cubrir el total del valor de la casa, momento en que los trabajadores se convertían en propietarios. Para la empresa, el "ahorro metódico" de los trabajadores era el mecanismo clave. En 1957 se informaba ampliamente de dos trabajadores, quienes con el ahorro metódico habían pasado a ser propietarios de sus casas en la Villa Presidente Ríos. Uno se llamaba Juan Ambrosio, tenía cuarenta ańos, estaba casado con Teresa y tenían cuatro hijos pequeńos, había ingresado a la planta en 1949, en la sección Muelles. En junio de 1953 ocupó la casa de la que llegó a ser propietario, por ella empezó pagando 3.000 pesos mensuales, hasta que alcanzó los 340.000 pesos, que era el valor del inmueble. Según la publicación de la compañía que hemos venido citando, "los descuentos mensuales no los ha sentido [el trabajador], tanto más cuanto que ha logrado convertirse en propietario, lo que era su mayor aspiración, ya que en esta forma ha podido entregar y garantizar para sus hijos y esposa, un porvenir más seguro" (Huachipato, 4[40], enero 1957, p. 23). 
El otro trabajador, también llamado Juan, casado con Mercedes y con cuatro hijos, estaba empleado en la planta desde 1948 y, desde 1953 ocupó la casa de la que llegó a ser propietario. Él también manifestaba haber "cumplido la más ansiada aspiración de toda su vida, de contar con una casa propia”. Y agregaba la publicación recién citada: "Le parece un sueño ver convertida en realidad esta aspiración" (p. 24). Estas noticias iban acompañadas además de una fotografía de los trabajadores y sus familias en las puertas de sus casas. Se convertían así en el símbolo del modelo de trabajador, es decir, un obrero responsable, disciplinado, buen padre de familia, modelo de masculinidad obrera que la empresa fomentaba y necesitaba.

FIGURA 3 | Trabajador y su familia que pasaron a ser propietarios en sector Higueras

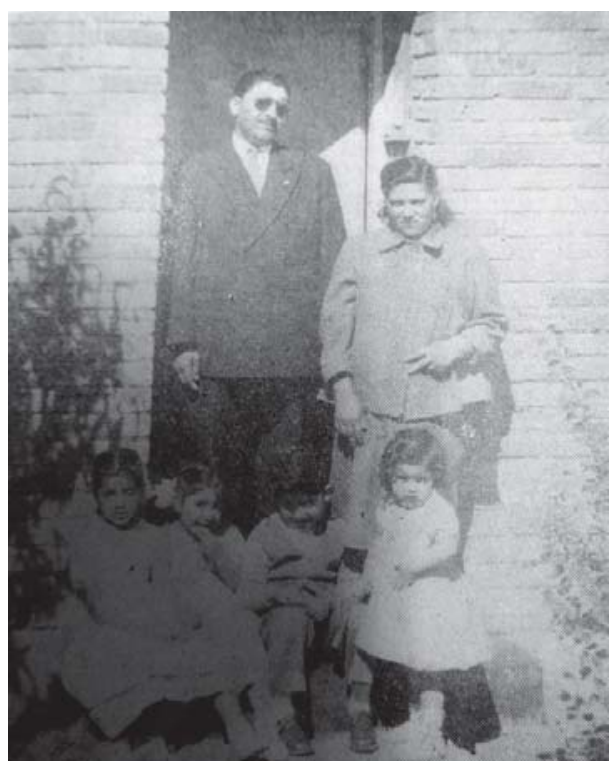

FUENTE HUACHIPATO, 4(40), ENERO I957, P. 23

La entrega de viviendas a los trabajadores fue altamente valorada, lo que aparece en los relatos actuales de extrabajadores.

A mí me contrataron el 8 de junio... Fue bonito, pero no tenía casa en ese tiempo, no tenía, eh, puras promesas habían, qué sé yo. Y sucedió un problema en una de esas partes, que se usaba mucho el pozo negro -no había baños así como ahora-, entonces teníamos en la mitad del patio... entonces estaba el lugar ahí pa’ lavar, un baño y qué sé yo. Entonces, tuvimos problemas que ese se desmoronó por el lado ¿ah? Y estos andaban cerca, mis dos hijas y mi hijo... Entonces yo invité a una visitadora... aproveché yo de hablar con ella, me atendió muy bien la viejita y, y cuando la llevé a la casa, entonces ella me dijo "no poh", me dijo, "usted tiene que salir de aquí, usted tiene que salir de este lugar", así que, como en un mes me tuvo fuera de ahí de donde vivíamos, y me llevaron a unos departamentos que había allá en Higueras, así que de ahí nos afirmamos, (...). De hecho, quisimos mucho ese departamento todos, porque, los cinco, decíamos "si alguna vez tenemos que volver, volveríamos a ese departamento" (Don Miguel, extrabajador de la Siderúrgica Huachipato). 
Esta situación se constituye en una memoria emblemática: muestra un cambio en los modos de vivir, que actúa como un eje transformador de las proyecciones de todo el núcleo familiar. La memoria es aquí un recurso central para construir futuro; por lo tanto, debe entenderse como un elemento de significación simbólica. En la práctica, la memoria emblemática se transforma en un puente entre la experiencia biográfica y la experiencia colectiva y sus significados (Stern, 2000).

La preocupación por el barrio iba más allá de la construcción y mantenimiento de las casas; también existió una política de intervención social, la que apoyaba o fomentaba las organizaciones de carácter barrial que iban surgiendo. La presencia de la empresa en el barrio era efectiva; así, se instaló en la Villa Presidente Ríos una oficina permanente del Servicio Social de la CAP, que tenía entre sus funciones la de "supervigilar y dirigir las actividades diversas y especialmente todo cuanto se relaciona con los Centros de Madres, Jóvenes y Vecinos y a cuyo frente está la Visitadora Social, Srta. Eliana Prado" (Huachipato, 3[37], octubre 1956, p. 4). Para 1956 el Centro de Madres contaba con 180 socias; se mantenía de rifas, beneficios, bailes sociales y otras actividades, cuyos rendimientos se utilizaban para adquirir materiales para los cursos que se dictaban (Bordados, Economía Doméstica, Tejidos, Corte y Confección, Moda Infantil, Juguetería, Flores y Peluquería), dirigidos a las esposas, hijas y parientes de los obreros de la CAP. También a cargo de esta oficina de Servicio Social funcionaba una Escuela de Párvulos a la que asistían sesenta niños de entre tres y seis ańos. Y funcionaban un Centro Juvenil y un Centro Deportivo donde participaban niños, jóvenes y adultos. En síntesis, el "Servicio Social está en continuo contacto con cada una de estas organizaciones y actúa según las circunstancias, como consejero, consultor, etc., procurando encauzar en la mejor forma las aspiraciones y actividades de los grupos. Se preocupa además de estudiar y resolver las dificultades individuales de todo orden que se producen en la comunidad" (Huachipato, 3[37], octubre 1956, pp. 4-5).

Todos estos mecanismos de intervención social muestran una empresa en donde el desarrollo y bienestar de sus trabajadores se había convertido en un mecanismo central para la constitución de un espacio laboral moderno y "bien constituido". En él, la familia pasaba a ser un mecanismo disciplinador y de control social central al momento de pensar y planificar, no solo el mundo del trabajo, sino también las relaciones sociales al interior del mundo productivo. Pero para que este mecanismo fuese efectivo era necesario "territorializar" las relaciones sociales esperadas. De allí que la casa-habitación aledańa al centro productivo se convirtiera en el modelo ideal, porque permitía no solo el mejor tránsito de un lugar al otro, sino que posibilitaba el construir vínculos sociales que iban derivando en un compromiso, lealtad e identificación con el espacio laboral. Fue mediante este proceso que se fue dando forma a la identidad "huachipatina" que se enraíza en el espacio construido, el que logra constituirse, además, en un espacio de construcción simbólica que muestra el modelo desarrollista como el más eficaz en la constitución del orden y paz social que se espera. 
FIGURA 4 | Poblaciones del sector Higueras

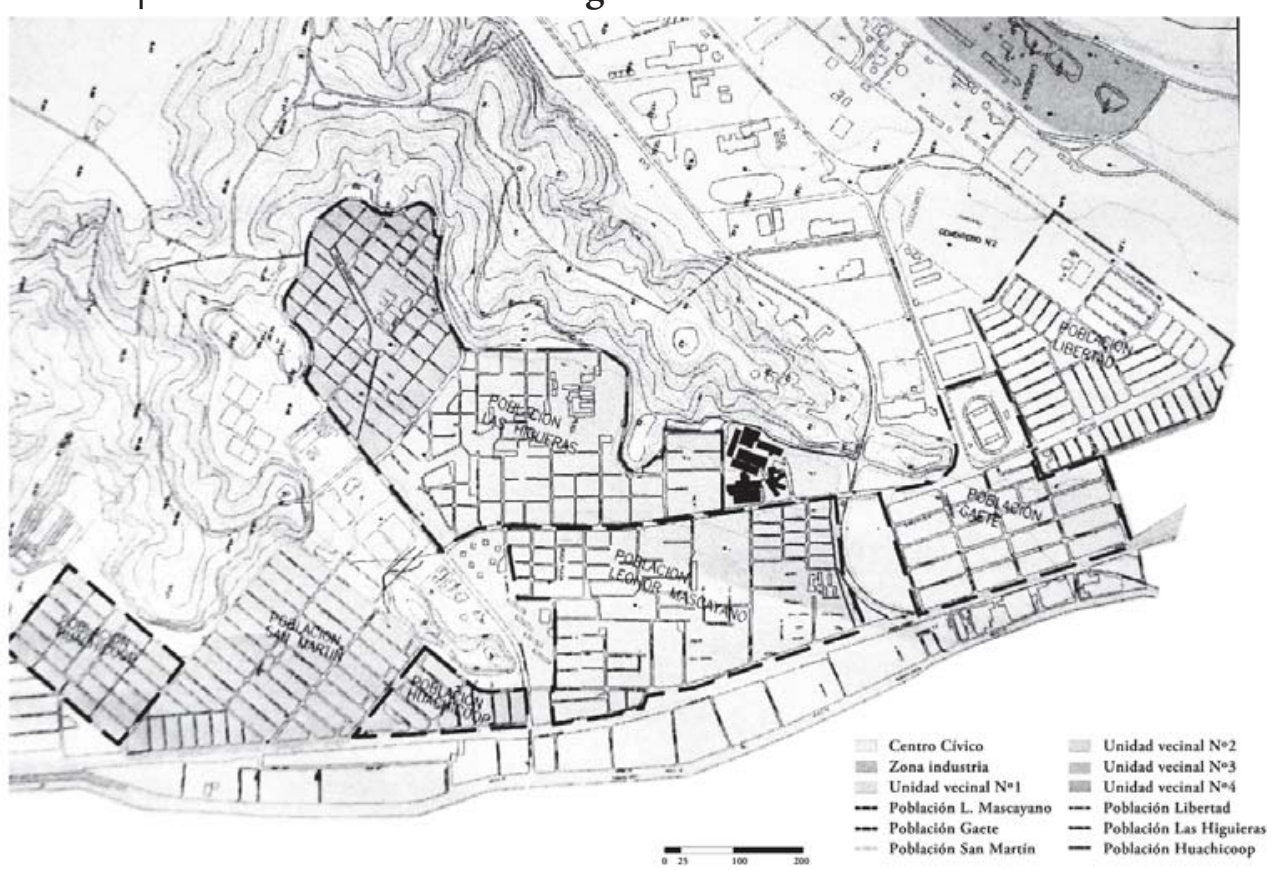

FUENTE P. REBOLLEDO (2OI2)

Como parte de su política, entonces, la Siderúrgica Huachipato tomó la decisión de propiciar o apoyar -desde lo que podríamos llamar un urbanismo paternalista- siete conjuntos residenciales: Villa Presidente Ríos, Villa Capataces cap, Villa Acero, Villa Collao, Villa Los Cóndores, Villa Llacolén y Villa Cerro Verde. Así, una de las principales contribuciones de Huachipato fue la configuración -material y simbólica- de un barrio. Barrio entendido en este caso como espacio relacional y con una identidad propia, distinguible en el tiempo y en el espacio regional, en el que los trabajadores y sus familias podían desarrollar la vida con un sentido de comunidad y donde se fueron tramando importantes sentidos de pertenencia y vínculos sociales. Pero donde también es factible ir verificando y actualizando las variaciones y persistencias en las significaciones que los actores construyen en torno a sus territorios, sobre todo en un escenario de grandes cambios históricos, sociales y biográficos. Sobre tales aspectos nos detendremos en el siguiente apartado.

\section{Significaciones sociales actuales en torno al barrio y su identidad en el contexto del proyecto urbano vinculado a la Siderúrgica Huachipato}

En este apartado interesa presentar algunos hallazgos que se desprenden de datos empíricos, derivados de la aplicación de encuestas a vecinos y vecinas que actualmente residen en las villas y entrevistas a extrabajadores de la siderúrgica. Las poblaciones seleccionadas fueron Huachicoop, Libertad, Gaete, Leonor Mascayano, Higueras y San Martín. Se encuestó a 320 personas; de ellas, 161 varones $(50,3 \%)$ y 159 mujeres $(49 \%)^{3}$.

Para la determinación de los encuestados se aplicó un muestreo no probabilístico, donde se operó 
CUADro 1 | Edad y lugar de asentamiento de habitantes de poblaciones de Talcahuano

\begin{tabular}{|l|c|c|c|c|}
\hline \multirow{2}{*}{\multicolumn{1}{c|}{ SECTOR }} & \multicolumn{3}{c|}{ EDAD } & \% \\
\cline { 2 - 5 } & $18-29$ & $30-59$ & 60 y más & Total \\
\hline Villa Huachicoop & 16 & 19 & 17 & 52 \\
\hline Libertad & 16 & 18 & 17 & 51 \\
\hline Gaete & 17 & 19 & 19 & 55 \\
\hline Leonor Mascayano & 17 & 22 & 14 & 53 \\
\hline Higueras & 18 & 19 & 17 & 54 \\
\hline San Martín & 17 & 21 & 16 & 54 \\
\hline
\end{tabular}

FUENTE ELABORACIÓN PROPIA A PARTIR DE ENCUESTA REALIZADA A POBLADORES/AS DE BARRIOS EN ESTUDIO

A continuación nos interesa dialogar con algunos resultados arrojados por la encuesta realizada. Cuando se les preguntó a los y las encuestados/as ¡cómo definen su barrio?, la tendencia predominante fue concebirlo como un lugar de pertenencia, con $41,7 \%$ de las preferencias, seguido más a la distancia por quienes lo definen como un lugar tranquilo y seguro, con 28,3\% de las preferencias (Gráfico 1).

\section{FIGURA 5 | Villa Higueras en la actualidad}

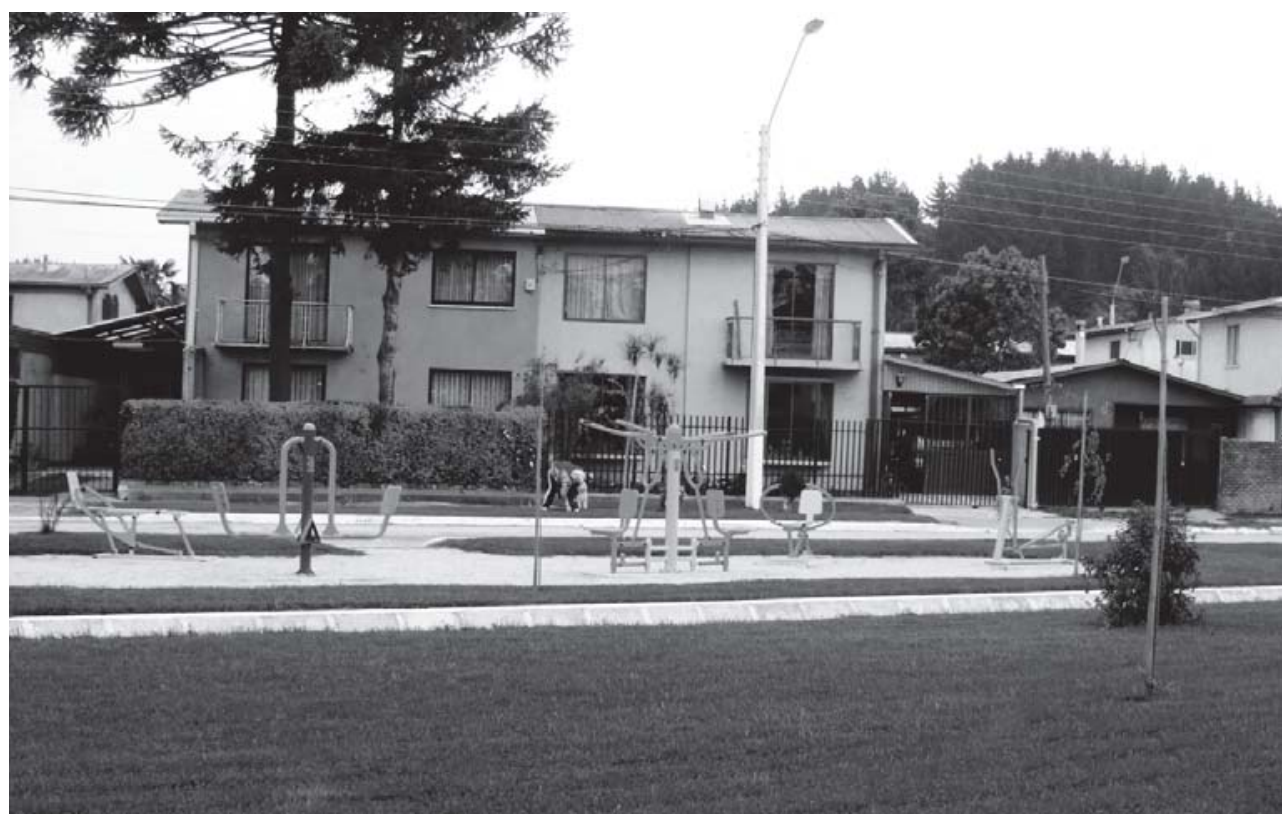

FUENTE FOTO TOMADA POR LOS AUTORES, IO NOVIEMBRE 20 I 2

Estos datos nos evidencian las significaciones que asignan los habitantes a los barrios, las que trascienden la materialidad física, es decir, la infraestructura y el

con un procedimiento de distribución por cuotas; la administración fue in situ según perfiles sociodemográficos (sexo, edad, años de residencia, sector, etcétera). 
equipamiento, para inscribirse en un sentido de pertenencia con su territorio. Este se configura como un espacio social materializado en una comunidad emocional, lo que permite un habitar tranquilo y seguro para la vida de las familias que tienen de ellos una experiencia vivida cotidiana. Los sentidos recogidos en los y las habitantes de los barrios encuestados nos sitúan en una espacialidad que muestra un tejido social que es vivenciado con orgullo y que se ha convertido en fuente de identidad territorial. Esta se puede observar y manifestar a pesar del transcurso del tiempo y de los grandes cambios y avatares que ha experimentado el Chile actual, y la región en particular.

\section{GRÁfico 1| Cómo definen su barrio}

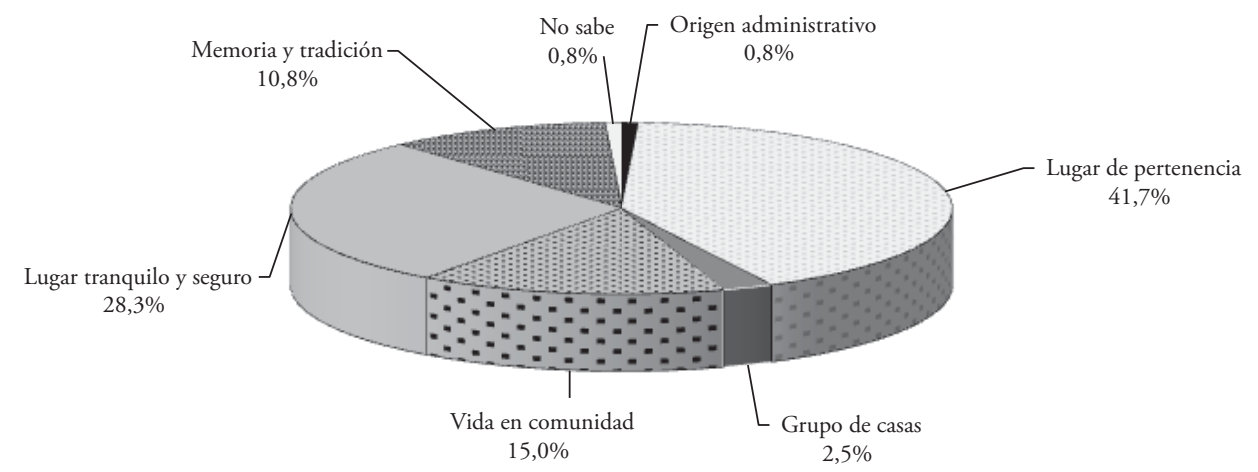

FUENTE ELABORACIÓN PROPIA A PARTIR DE ENCUESTA REALIZADA A POBLADORES/AS DE BARRIOS EN ESTUDIO

Cuando se pregunta por el vínculo que poseen con la Siderúrgica Huachipato, como podemos ver en el Gráfico 2, la mayoría destaca que tienen un familiar que trabaja en la empresa, con un promedio en todos los territorios de casi $50 \%$, que llega a casi $60 \%$ en algunas de las villas, como Huachicoop y Leonor Mascayano. Si sumamos las categorías de "trabajó", o "un familiar trabaja", las cifras alcanzan en algunos territorios a más de $80 \%$. Esto nos está mostrando que la vinculación sigue siendo muy estrecha con la Siderúrgica. Aún existe una pertenencia laboral, una experiencia cotidiana donde la Siderúrgica sigue siendo palpable en la memoria colectiva. No es solo una presencia de la empresa como infraestructura histórica, sino una experiencia vivida en los espacios cotidianos hasta hoy, marcada por un sentido que traspasa las generaciones, constituyéndose como una experiencia intergeneracional.

En este mismo plano, cuando los y las encuestados/as deben pronunciarse por la influencia de Huachipato en la formación del barrio, en el caso de las villas Huachicoop, Leonor Mascayano, Higueras y San Martín, para la mayoría (cercanas al 80\%) la influencia es muy relevante y significativa (Gráfico 3). En estas poblaciones la presencia simbólica de la empresa en el barrio es muy alta, lo que permite la construcción de una memoria emblemática, materializada en un reconocimiento de la obra realizada por la empresa en el territorio. Pero es significativo consignar que esto se rememora como un proyecto colectivo, donde la experiencia de los trabajadores es un engranaje más del proceso. Así, la experiencia histórica compartida 
aparece como un pilar central en el éxito de la experiencia del modelo desarrollista en el territorio estudiado, más allá de los análisis que se detienen en las limitaciones estructurales que el modelo tuvo.

GRÁfICo 2| Vínculo con la Siderúrgica Huachipato

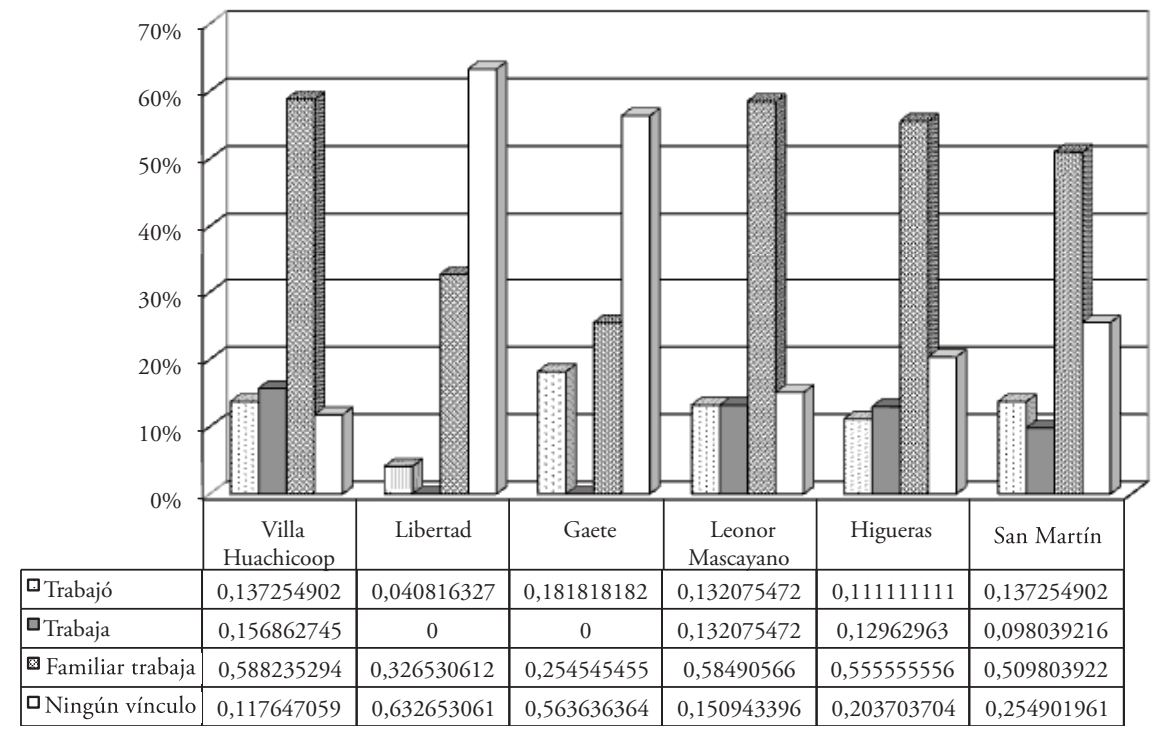

FUENTE ELABORACIÓN PROPIA A PARTIR DE ENCUESTA REALIZADA A POBLADORES/AS DE BARRIOS EN ESTUDIO

\section{GRÁFICO 3| Influencia de la Siderúrgica Huachipato en la formación del barrio}

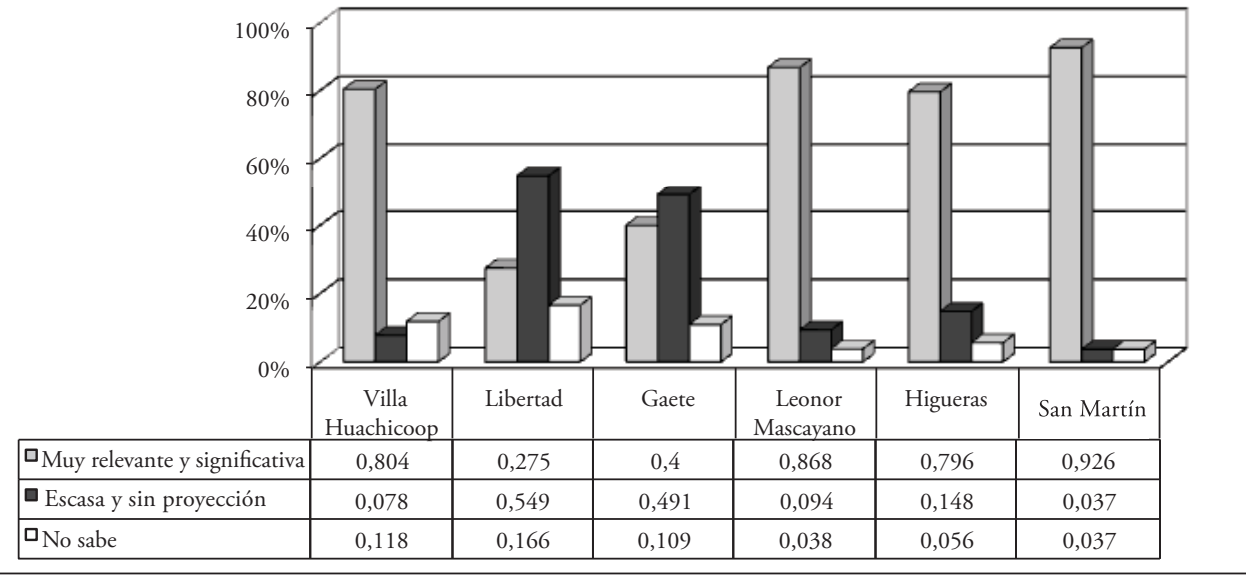

FUENTE ELABORACIÓN PROPIA A PARTIR DE ENCUESTA REALIZADA A POBLADORES/AS DE BARRIOS EN ESTUDIO

En este mismo plano, cuando los y las encuestados/as deben pronunciarse por la influencia de la Siderúrgica, aparece que para quienes todavía habitan en estos barrios la presencia de la empresa es relevante y positiva. Ello queda también de manifiesto en los discursos de algunos extrabajadores de la Siderúrgica Huachipato ${ }^{4}$

Alguna de las entrevistas fueron realizadas en el marco de la Memoria para optar al título de 
y que se refieren al plano del desarrollo humano y social alcanzado por los trabajadores en el periodo de consolidación del proyecto:

Lo bueno de la compañía es que hay muy pocas empresas que a uno lo contratan de por vida; muy pocas empresas a uno le dan las oportunidades para ser lo que uno quiera, porque yo pude haber llegado, como lo decía, haber estudiado y haber sido ingeniero; haber sido a lo mejor un ejecutivo de la misma compañía (...) hay que pensar, hay que retrotraerse al ańo sesenta y pensar que Huachipato, toda la gente que se contrató era gente que necesitaba trabajar, las condiciones de trabajo eran en su 90\% -hablando así de cosas actuales- brutanteque nomás (...). Todas esas cosas hacen que la evolución digamos del personal trabajador fue vertiginosa y logramos, yo diría en lo mío como persona, Huachipato me lo dio todo, desde la educación para arriba, todo lo que yo quise hacer. Conozco el mundo -gracias a Dios- a mi trabajo, a mi esfuerzo, pero gracias a la compañía también, que me abrió las puertas. Si mañana tuviera que volver a trabajar, la primera solicitud la enviaría a la compañía (Don Eleazar, extrabajador Siderúrgica Huachipato).

Yo, como te digo, bien agradecido, yo soy agradecido en ese sentido, porque el que quería, nadie se estancaba ahí en Huachipato (...) hay empleos donde actualmente tampoco existe eso. Nadie se estancaba, usted entra como ayudante, como jornalero, puede estar cuatro años, y a los cuatro años ya principian a tomarlo en cuenta según su forma de trabajar en la planta; por decir, le tomaban cosas, ahora parece que no lo toman en cuenta nadie. Pero, como le dijera, le toman en cuenta cuando la persona es leal en el trabajo. A ti te dan un trabajo y tú lo haces lo mejor posible y, a la vez, ser constante con el trabajo (...), Y la compañía, como te digo, te daba por seguir una carrera, cosa que el hombre vaya aumentando su sueldo, o salga en las mejores condiciones cuando termina. No sé actualmente, sinceramente. Tengo un hijo que trabaja en Huachipato, él me dice que las cosas han cambiado totalmente (...) nadie está seguro de su trabajo (Don Juan, extrabajador Siderúrgica Huachipato).

La situación es diferente en las poblaciones Gaete y Libertad. Allí, a pesar de la cercanía física con la empresa, la influencia es escasa y sin proyección, categoría que alcanza cifras cercanas al 50\%. Ello muestra que en estos territorios hay una memoria histórica que releva menos la presencia de la empresa; en ellos no se distingue la construcción de una memoria emblemática. Esta diferencia de percepciones se explica por una experiencia histórica distinta de vínculo con la empresa. Si existe algún lazo, este tiende a ser negativo, ya que el emplazamiento de las poblaciones Gaete y Libertad no las protege ambientalmente: es más cercano a las faenas, sin mayor separación respecto de ellas, situadas como están al otro lado de los cerros que protegen al sector Higueras de los efectos contaminantes de la Siderúrgica. Tampoco constituyen barrios obreros modernos, ni están marcados por el modelo desarrollista. Más bien son sectores que quedaron al margen de los beneficios de ese modelo, al ser territorios con una precaria urbanización, casi sin servicios ni áreas verdes, todo ello explicaría el poco arraigo con la empresa en dichos sectores.

Socióloga de la estudiante Gabriela Ramos, durante el 2010, cuya Profesora Guía fue la Dra. Alejandra Brito. 
FIGURA 6 | Monumento a los trabajadores en Villa Higueras

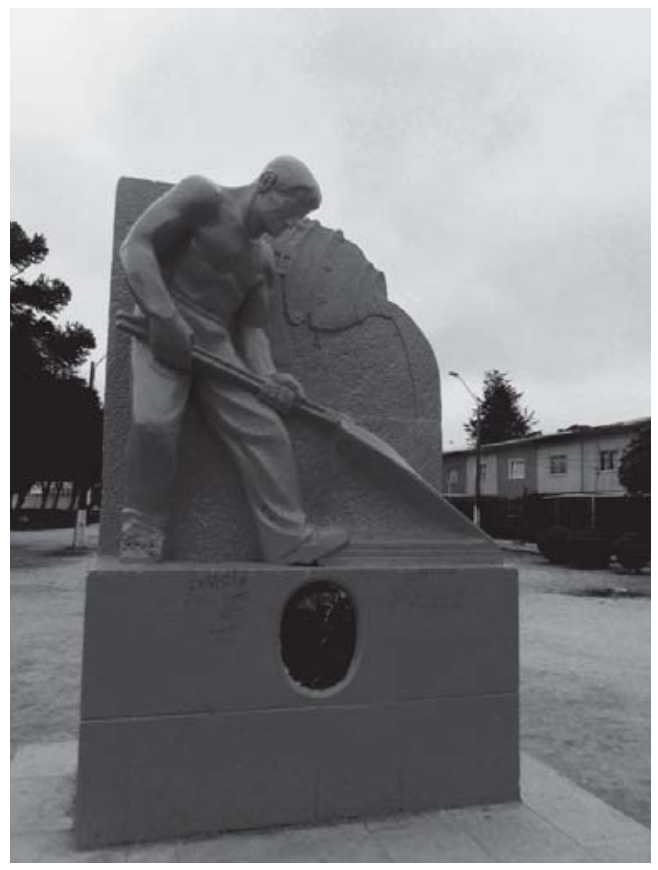

FUENTE FOTO TOMADA POR LOS AUTORES, IO NOVIEMBRE 20 I 2

Ahora bien, cuando se les pregunta por la adscripción identitaria asociada a su barrio, la mayoría $(44,1 \%)$, y sin distinción por sector, señala que la identidad de su barrio es diversa; muy por debajo se destaca la identidad obrera del barrio $(7,6 \%)$, a pesar de que ese componente aparece como eje en la concepción urbana original del sector (Gráfico 4).

\section{GRÁFICO 4| Identidad del barrio}

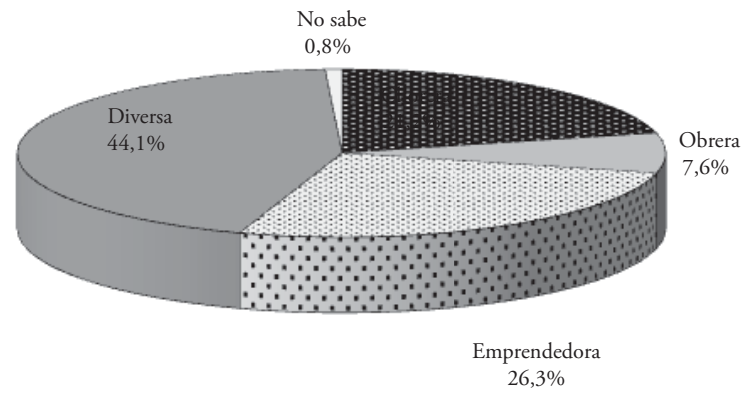

FUENTE ELABORACIÓN PROPIA A PARTIR DE ENCUESTA REALIZADA A POBLADORES/AS DE BARRIOS EN ESTUDIO

La pérdida del carácter obrero tradicional de los barrios en el caso en estudio, esto es, la transformación de su identidad, no puede ser explicada desde una perspectiva evolutiva, ni tampoco por el desarraigo producto de la globalización. En este caso 
específico puede comprenderse más bien como un proceso deliberado que avanzó a la constitución de una elite obrera exitosa, debido a la gran cantidad de beneficios que reportó para los trabajadores y sus familias el ser parte de Huachipato. Con el acceso a bienes y servicios difíciles de alcanzar para la mayoría del mundo obrero tradicional, dejaron de pertenecer a esa cultura que, históricamente, estaba marcada por el conflicto permanente por mejores condiciones de vida. Este proceso pone de manifiesto una clara movilidad ascendente, visible en un estándar de vida que aleja a los trabajadores de Huachipato de la mayoría de los obreros del país, cuestión que se hace patente con el desaparecimiento de la noción de "barrio obrero", como fue el diseño original de los espacios construidos.

Lo anterior también marca una diferencia entre las poblaciones Huachicoop, Leonor Mascayano, Higueras y San Martín, por un lado, y los barrios Gaete y Libertad, por el otro. Con la menor calidad urbana e imagen empobrecida que presentan estos últimos sectores, la identidad obrera se mantiene con niveles más altos $(20 \%)$, a la vez que sus habitantes se reconocen en el territorio más amplio, como lo es Talcahuano (identidad "chorera" $5,30 \%$ ), que en el contexto regional se identifica como una población más popular.

Por su parte, al preguntarles a los habitantes de las poblaciones qué es lo que más valoran del barrio, indistintamente del sector, la respuesta más recurrente es sus vecinos (35\%), seguida por la tranquilidad del mismo (32,2\%), lo que está en relación con el sentimiento de espacio construido, donde el sentido de comunidad está presente y, por ello, existe una valoración muy positiva de los vecinos/as de la composición social y humana del territorio (Gráfico 5).

\section{GRÁfICO 5| Lo que más valora de su barrio}

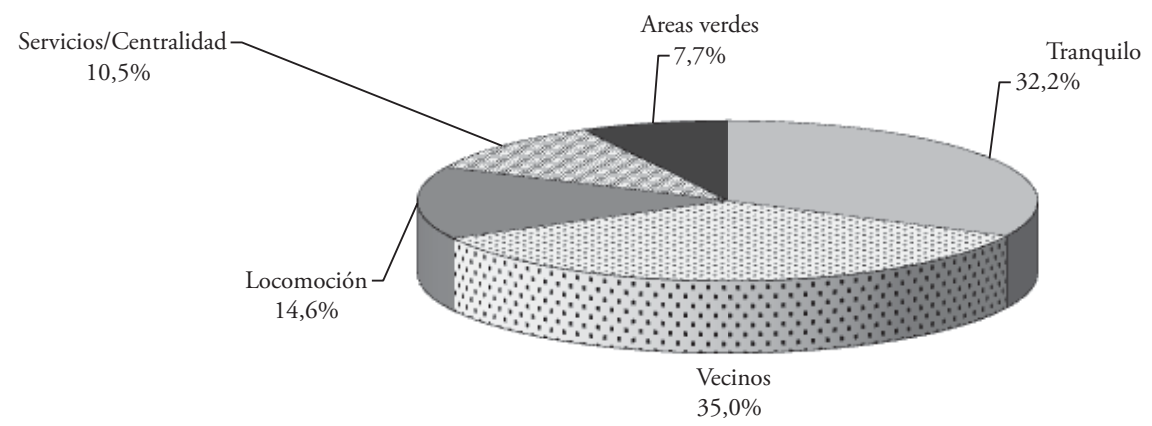

FUENTE ELABORACIÓN PROPIA A PARTIR DE ENCUESTA REALIZADA A POBLADORES/AS DE BARRIOS EN ESTUDIO

Respecto de la dimensión que evalúa arraigo y pertenencia barrial, en su mayoría los y las encuestados/as sostienen que si tuvieran los recursos para trasladarse de

5 En un uso coloquial, "chorero" es el gentilicio de los habitantes de Talcahuano; está relacionado con la extracción del choro hasta mediados del siglo xx. El término se aplica también a quienes extraen este molusco. 
vivienda no se cambiarian (Gráfico 6), básicamente porque conciben como una riqueza y un valor el vivir en el barrio que habitan. El único caso y sector donde los encuestados plantearon que se cambiarían de casa a otra más confortable lejos del barrio fue el de la población Libertad, lo que confirma el poco arraigo existente, en tanto la población no cuenta con los servicios y espacios que permitirían una percepción más positiva del lugar.

\section{GRÁfICO 6| Si tuviera recursos, ¿se cambiaría de barrio?}

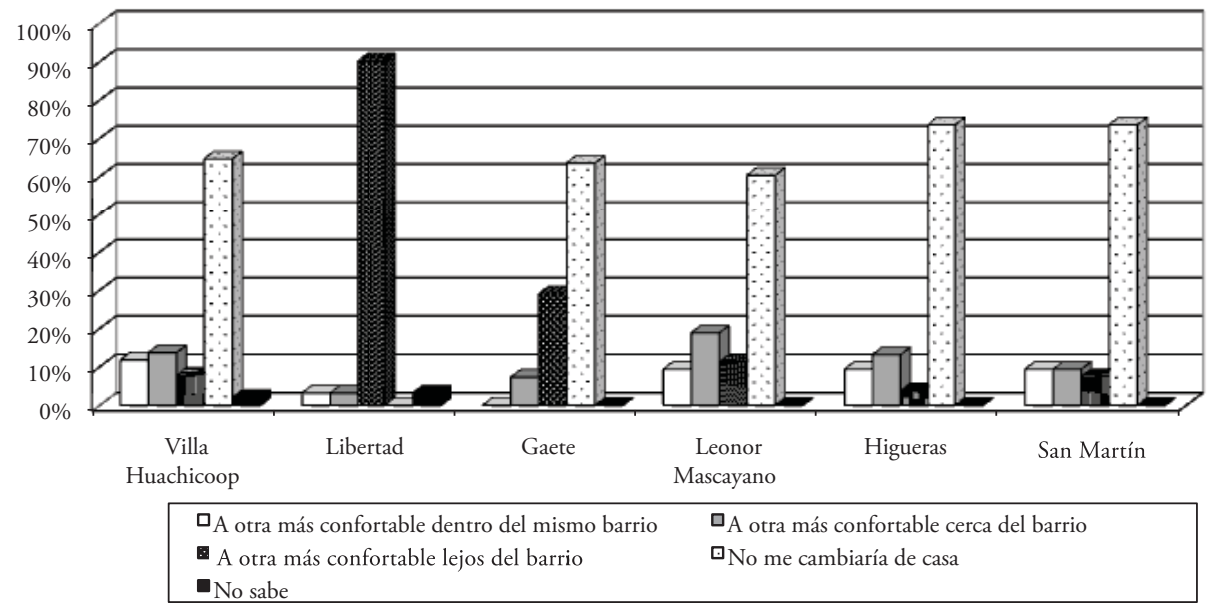

FUENTE ELABORACIÓN PROPIA A PARTIR DE ENCUESTA REALIZADA A POBLADORES/AS DE BARRIOS EN ESTUDIO

Finalmente, sobre perspectiva de futuro del barrio, destaca en su mayoría una percepción según la cual el futuro del barrio será mejor que en la actualidad (Gráfico 7), salvo en el caso de las poblaciones Libertad y Gaete, donde prevalece una proyección poco optimista de su devenir.

\section{GRÁFICo 7| Percepción de futuro}

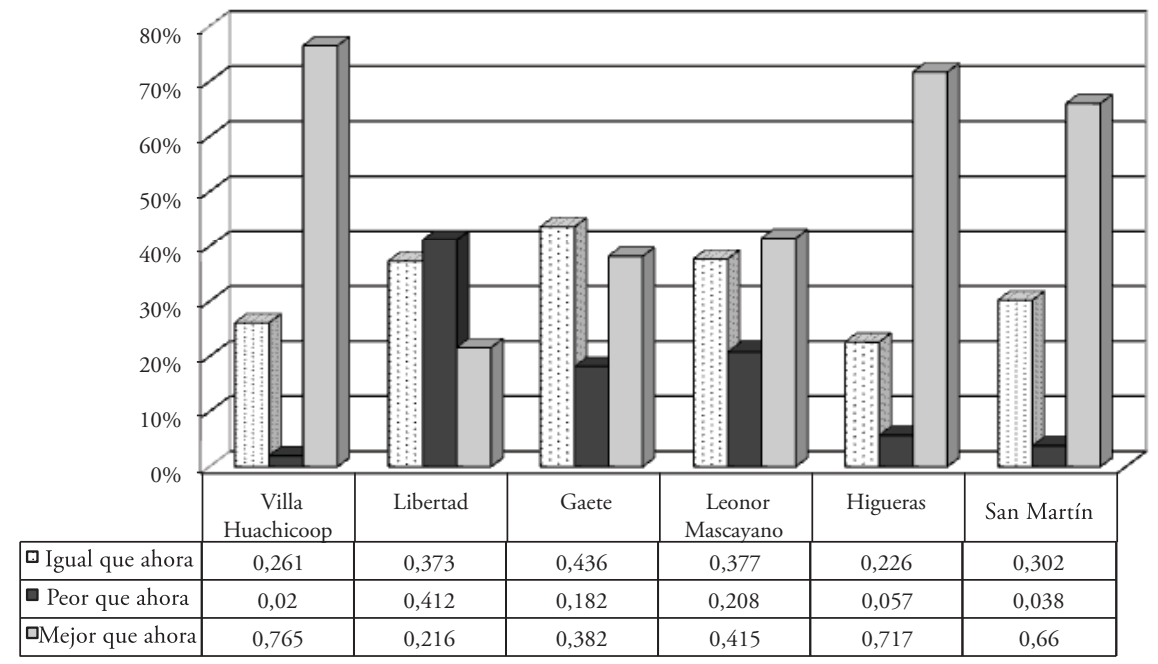

FUENTE ELABORACIÓN PROPIA A PARTIR DE ENCUESTA REALIZADA A POBLADORES/AS DE BARRIOS EN ESTUDIO 
Si nos detenemos a analizar las significaciones actuales atribuidas al barrio por parte de quienes lo habitan (Gráficos 5, 6 y 7), nos damos cuenta de que persiste una valoración muy positiva del espacio vecinal, pues los residentes aprecian considerablemente a sus vecinos, ven con optimismo el futuro y, en el balance, no se cambiarían de barrio si tuvieran la posibilidad de hacerlo. Esto nos muestra la existencia de un potente arraigo donde el territorio se convierte en un espacio vivencial y experiencial, pues la gente quiere seguir viviendo en los lugares en donde ha ido forjando su memoria social y su identidad colectiva. Lo que se desprende de ello es un importante sentido afectivo respecto del barrio, en tanto este no se define por su geometría o sus fronteras perimetrales, sino que se materializa por el valor asignado a quienes constituyen su paisaje cotidiano, esto es, sus habitantes.

En el fondo, lo que afirmamos con Lefebvre (1968) es que "es más fácil construir ciudades que vida urbana. La separación funcional destruye la complejidad de la vida" (p. 10). Y si volvemos a la geografía de la Vida Cotidiana (GVC), donde el significado del lugar y la construcción de subjetividad espacial adquieren un centralidad capital; donde los sentidos intersubjetivos elaborados por los actores sociales "en" y "con" el lugar son tan o más importantes que la llamada realidad material; podemos plantear que el denominado "sentimiento de arraigo" expresado en la percepción de los habitantes no es otra cosa que la estabilidad residencial expresada intergeneracionalmente. Es decir, se trata de la persistencia de una memoria emotiva espacializada, que se hace emblemática, con un orgullo -nostálgico- que no se deja borrar por los procesos de modernización, expansión urbana o incluso por el eventual deterioro de los espacios físicos mediados por el paso del tiempo. Existe un recuerdo de una época de gloria, que nos hace reflexionar en torno a sus actuales fisuras, sobre todo en el marco de un modelo tardocapitalista que enfatiza la incertidumbre, la precariedad y el riesgo. A pesar de ello, el modelo anterior y los actores que lo sustentaban lograron facilitar la producción de vida urbana y no solo de infraestructura y equipamiento urbano, relevando así los aspectos simbólicos, participativos, de heterogeneidad e intercambio social que caracterizan la producción de vida urbana, y cuyos rasgos importantes permanecen visibles hasta la actualidad.

La pregunta que nos interesa dejar planteada es cómo comprender la subjetividad de los actuales residentes de los barrios estudiados, vinculados con la evolución del modelo de desarrollo que sustentó la creación de dicho espacio urbano, el que estaba orientado a la creación de espacio público de calidad, con equipamiento y conectividad óptimos, y que en lo sucesivo fueron generando sentido de vecindad y comunidad. Entender los éxitos o fracasos del modelo desarrollista en un ejemplo emblemático de implementación del mismo, la Siderúrgica Huachipato, representa una forma particular de mirar los procesos. A nivel nacional, los análisis de la implementación del modelo de la industrialización por sustitución de importaciones (ISI) nos han mostrado que dicha propuesta tuvo importantes desajustes que llevaron finalmente a su fracaso. Entre los más relevantes está que el objetivo central del modelo era disminuir la dependencia con los capitales extranjeros, fundamentalmente el norteamericano, mientras el resultado de su implementación fue el inverso: se aumentó el endeudamiento, fortaleciéndose la dependencia al estar sujeto el funcionamiento de las empresas estratégicas, como la producción de acero, 
a dichos capitales. Huachipato se pudo instalar gracias a los préstamos del Eximbank, y toda la primera etapa de funcionamiento se hizo bajo la supervisión de consultoras norteamericanas, condición explícita de los préstamos contraídos. Pero esta evaluación de nivel macroeconómico no es la misma que realizan quienes se beneficiaron de las estrategias productivas y laborales de la instalación de la empresa. Las políticas de bienestar social y la puesta en marcha de un modelo de relaciones laborales de carácter fordista dejó en la experiencia de quienes lograron acceder a dichos beneficios una visión muy positiva del proceso, fundamentalmente porque la materialización de logros les posibilitó acceder a un mejor estándar de vida, mediante un claro proceso de movilidad social ascendente. Por lo mismo, aquellos que quedaron fuera de ese proceso de "expansión de beneficios" no lograron establecer vínculos potentes y sustentables en el tiempo con los espacios, razón por la cual despliegan una percepción más negativa de su propio devenir. Ejemplo de ello es el caso de los habitantes de las poblaciones Gaete y Libertad, que se convirtieron en el patio trasero de los logros del modelo, con un acceso limitado a sus beneficios. De ahí que su arraigo con el territorio sea más precario y opuesto al de los habitantes de sectores más emblemáticos, como Higueras.

Por último, queremos relevar como hallazgo (y paradoja) la persistencia de un compromiso emocional de parte de los vecinos con su barrio en el caso de Huachicoop, Leonor Mascayano, Higueras y San Martín, y que no solo es posible identificar en los residentes fundacionales, porque -a pesar del fracaso del modelo IsI- se traspasa y valida intergeneracionalmente. Así, la pregunta que queda es si estamos frente a una mirada nostálgica de un pasado glorioso, o bien si al compararse actualmente con sus "otros" más cercanos - las poblaciones Libertad y Gaete- perciben comparativamente una distinción importante en cuanto a calidad de vida urbana y progreso social.

\section{FIgURA 7 Población Gaete en la actualidad}

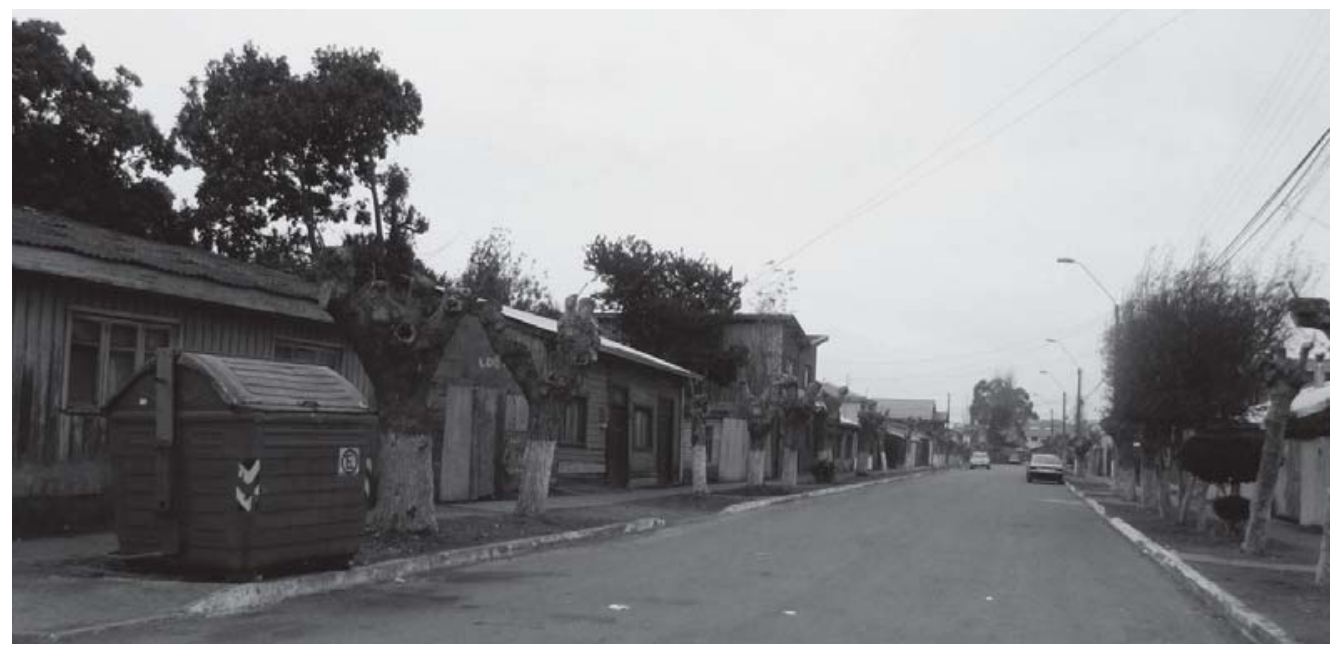

FUENTE FOTO TOMADA POR LOS AUTORES, IO NOVIEMBRE 20 I 2 
FIgURA 8 | Población Libertad en la actualidad

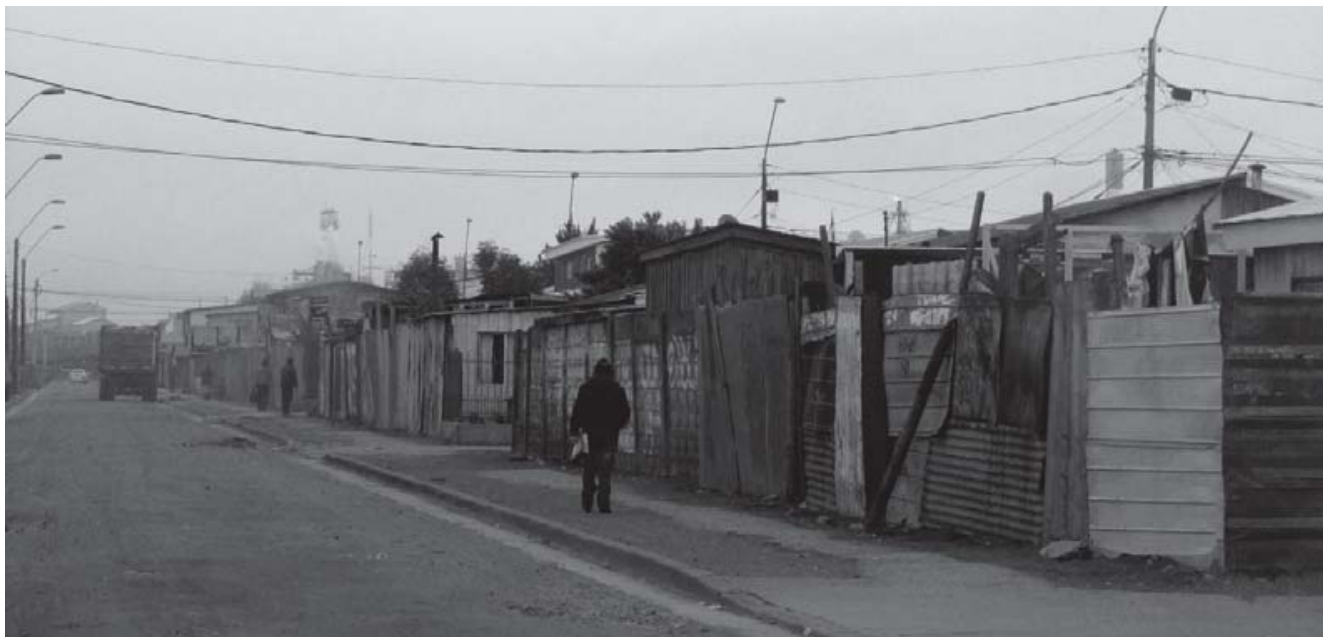

FUENTE FOTO TOMADA POR LOS AUTORES, IO NOVIEMBRE 20 I 2

En nuestra opinión, estamos frente a un grupo humano que se reconoce partícipe de una forma distinta de concebir la inserción de los trabajadores en las políticas de desarrollo, y donde el territorio constituye -en su autopercepción- un recurso de actualización permanente de la memoria social y un valor tangible que promueve vínculos, afectos, seguridades, confianza en el futuro e integración con los otros y el entorno. Ello no quiere decir, sin embargo, que las fricciones y la heterogeneidad estén ausentes. Por el contrario, precisamente porque esos componentes están presentes en dicho territorio es que hay vida urbana.

Considerando lo anterior es que planteamos -sobre todo para el caso de la población Higueras- la conformación de un inédito y emblemático modo de habitar el espacio en la escala del Gran Concepción, aspecto que aún es posible observar a partir de ciertos signos y elementos que venimos describiendo en este texto. Esto se hace mucho más significativo si se lo piensa en un contexto social donde la tendencia es al desanclaje de las relaciones sociales y la fragmentación de las geografías y el espacio urbano. De ahí el desafío por explorar nuevos lenguajes interdisciplinarios que permitan comprender relacionalmente los procesos históricos de cambio estructural, las dinámicas de producción del espacio circunscrito a momentos y escenarios específicos, y las prácticas-significaciones que tejen y traman cotidianamente los propios actores respecto de su experiencia vivida espacializada. 


\section{Referencias bibliográficas}

Abbe, F. \& Kaminoff, R. (1983). Place-identity: physical world socialization of the self. Journal of Environmental Psychology, 3(1), 57-83. doi: 10.1016/S0272-4944(83)80021-8

Aliste, E. (2011). Territorio y huellas territoriales: una memoria del espacio vivido en el Gran Concepción, Chile. Desenvolvimento e Meio Ambiente, 23, 25-38. En http://www. socioambiental.cl/sites/default/files/documentos/20911-79618-1-PB_0.pdf

Echeñique A. \& Rodríguez, C. (1990). Concepción. Historia de la Compañia de Aceros del Pacifico S.A. Huachipato: consolidación del proceso siderúrgico chileno 1905-1950. Santiago de Chile: CAP S.A. de Inversiones.

Fuentes, P. (2006). Mort de la rue o la introducción de los principios del urbanismo moderno en Chile. Ejercicios de la época. Revista Urbano, 9(14), 27-33 En http://www.redalyc. org/articulo.oa?id=19891406.

Fuentes, P. \& Pérez, L. (2007). Vivienda obrera en Concepción: La Villa Presidente Ríos, primera ciudad moderna en Chile. En R. Hidalgo \& M. J. Castillo (Eds.), 1906-2006: 100 años de vivienda y barrio (pp. 85-106). Santiago de Chile: Universidad Católica de Chile, U. Andrés Bello y U. Central de Venezuela.

Goffman, E. (1971). La presentación de la persona en la vida cotidiana. Buenos Aires: Amorrortu. Gumuchian, H. (1991). Représentations et aménagement du territoire. París: Económica.

Hiernaux-Nicolas, D. (2008). Geografía objetiva versus geografía sensible: trayectorias divergentes de la Geografía Humana en el siglo xx. Revista da ANPEGE, 4, 27-38. En http://anpege.org.br/revista/ojs-2.2.2/index.php/anpege08/article/view/9

Hiernaux-Nicolas, D. \& Lindón, A. (2006). Introducción. La geografía humana: un camino por recorrer. En D. Hiernaux \& A. Lindón, A. (Eds.), Tratado de geografía humana (pp. 7-22). Barcelona: Anthropos Editorial/Universidad Autónoma Metropolitana (UAM)-Iztapalapa, México.

Lefebvre, H. (1968). El derecho a la ciudad. Barcelona: Ediciones Península.

Lindón, A. (2006). Geografías de la vida cotidiana. En D. Hiernaux \& A. Lindón, A. (Eds.), Tratado de geografía humana (pp. 356-398). Barcelona: Anthropos Editorial/ Universidad Autónoma Metropolitana (UAM)-Iztapalapa, México.

Mazzei de Grazia, L. (1997). Antiguos y nuevos empresarios en la Región de Concepción en el siglo XIx. Revista de Historia, 7(7), 117-187.

Pacheco, A. (2003). Economía y sociedad de Concepción Siglo XIX: Sectores populares urbanos, 1800-1885. Concepción: Universidad de Concepción, Fac. de Humanidades y Arte, Dpto. de Cs. Históricas y Sociales, Chile.

Pérez, L. \& Salinas, E. (2007). Crecimiento urbano y globalización: transformaciones del área metropolitana de Concepción, Chile, 1992-2002. Scripta Nova. Revista Electrónica de Geografía y Ciencias sociales, 11(251). En http://www.ub.edu/geocrit/sn/sn-251.htm

Proshansky, H. M. (1978). The city and self-identity. Environment and Behavior, 10(2), 147169. doi: $10.1177 / 0013916578102002$

Proshansky, H. M., Fabian A. K, \& Kaminoff, R. (1983). Place-identity: Physical world socialization of the self. Journal of Environmental Psychology, 3(1), 57-83. doi: 10.1016/ S0272-4944(83)80021-8 
Rebolledo, P. (2012). Contribuciones de la empresa Huachipato a la formación del espacio residencial en Concepción. Estudio de cuatro conjuntos residenciales. Seminario de grado, carrera de Arquitectura, Universidad de Concepción.

Reguillo, R. (1991). En la calle otra vez. Las bandas: identidad urbana y usos de la comunicación. Tlaquepaque, Jalisco, México: Instituto Tecnológico y de Estudios Superiores de Occidente (ITESO).

Reguillo, R. (1996). La construcción simbólica de la ciudad: sociedad, desastre y comunicación. Tlaquepaque, Jalisco, México: Instituto Tecnológico y de Estudios Superiores de Occidente (ITESO).

Revista Huachipato. Compañía de Acero del Pacífico. Impreso en los Talleres de la Litografía Concepción S.A., Concepción (Chile). Años de publicación 1953 a 1971, n. ${ }^{\text {os }} 1$ al 125.

Seamon, D. (1979). A geography of the lifeworld: movement, rest and encounter. Londres: Croom Helm/Nueva York: St. Martin's Press.

Silva, G. (1967). La villa del puerto Higueras. Concepción: Editorial El Sur.

Soja, E. (1997). El tercer espacio. Ampliando el horizonte de la imaginación geográfica. Conferencia dictada en el $6^{\circ}$ Encuentro de Geógrafos de América Latina, 17 al 21 de marzo de 1997, Buenos Aires. Presentada por S. Albino \& A. Barsky. Reproducida en Geographikós, 8(2 semestre 1997), editada por A. Barsky. En http://servidor-opsu. tach.ula.ve/profeso/sant_arm/l_c/pdf/el_terc.pdf

Stern, S. (2000). De la memoria suelta a la memoria emblemática: hacia un recordar y el olvidar como proceso histórico (Chile 1973-1998). En M. Garcés, P. Milos, M. Olguín, J. Pinto, M. T. Rojas \& M. Urrutia (Comps.), Memoria para un nuevo siglo. Chile, miradas a la segunda mitad del siglo XX (pp. 11-33). Santiago: LOM Ediciones.

Tello, R. (2003). La ciudad como escenario de representación cultural: prácticas urbanísticas de perpetuación. En M. Nash \& D. Marre (Eds.), El desafio de la diferencia: representaciones culturales e identidades de género, raza y clase (pp. 213-224). Bilbao: Universidad del País Vasco, Servicio de Publicaciones. Artículo en http://www.desafio.ufba.br/gt4-017.html

Valera, S. (1994). El concepto de identidad social urbana: una aproximación entre la Psicología Social y la Psicología Ambiental. Anuario de Psicología (Universidad de Barcelona, Barcelona), 62, 5-24. En http://gemma.atipic.net/pdf/330AD10809K.pdf

Vivallos, C. \& Brito, A. (2011). Configuración y estructura del espacio urbano del Gran Concepción. Hilario Hernández Gurruchaga y los estudios regionales. Revista de Humanidades (Universidad Nacional Andrés Bello, Santiago), 23 (junio), 119-133. En https://www.google.com/url?q=http://www.redalyc.org/articulo. oa\%3Fid\%3D321227218007 